two year history of recurrent painful violet erythema nodular lesions associated with high levels of RF (latex; range 1048-2000 U/ml). She denied asthenia, weight loss, fever, and had no respiratory or articular complaints.

On physical examination many scattered, painful, tender and slightly raised violet subcutaneous nodules were found on the posterior aspects of both calves. The patien was afebrile. Results of cardiopulmonary and abdominal explorations were unremarkable. White blood cell and platelet count were normal. The haemoglobin was $126 \mathrm{~g} / \mathrm{l}$ and erythrocyte sedimentation rate $18 \mathrm{~mm} / 1 \mathrm{st} \mathrm{h}$ Urea nitrogen, creatinine, glucose, bilirubin aspartate transaminase, alkaline phosphatase, cholesterol, triglycerides, calcium, and phosphorus were all normal. A positive purified protein derivative skin test, antinuclear antibodies, cryoglobulins, and serum complement (C3 and C4) were unremarkable. Serum RF determined by turbidimetric immunoassay was $2048 \mathrm{U} / \mathrm{ml}$ (Quantex RF plus-latex; WHO units). Rheumatoid factor determined by haemagglutination on slide (modified Waaler-Rose procedure) was $256 \mathrm{U} / \mathrm{ml}$ (Celarkit AR; Biokit SA, Spain; WHO units).

Chest films showed a fibroproductive pattern affecting both upper lung lobes with out paratracheal or perihiliary adenopathies. Microscopic examination of three sputum specimens stained by Ziehl-Neelsen's method disclosed no acid-fast bacilli. A wedge biopsy of one skin nodule was performed and pathological examination disclosed a granulomatous panniculitis consistent with erythema induratum (figure). Ziehl-Neelsen and auramine-rhodamine stains were negative. Sputum cultures in LöwensteinJensen medium grew $M$ tuberculosis.

Specific daily treatment with rifampicin $600 \mathrm{mg}$, isoniazid $300 \mathrm{mg}$, and pyrazinamide $1500 \mathrm{mg}$ was started and continued for two months. Rifampicin and isoniazid was continued for four more months at the same dose. The two Mantoux tuberculin skin tests (5 tuberculin units of purified protein derivative) performed while the patient was receiving chemotherapy were negative. At the end of the first, third, and sixth month of treatment, RF had decreased to 600,200 and $44.2 \mathrm{U} / \mathrm{ml}$ respectively. The patien remained asymptomatic, and skin lesions healed leaving a pigmented scar.

Erythema induratum, included in the tuberculids, is not a 'true' manifestation of skin tuberculosis because acid-fast bacilli are not

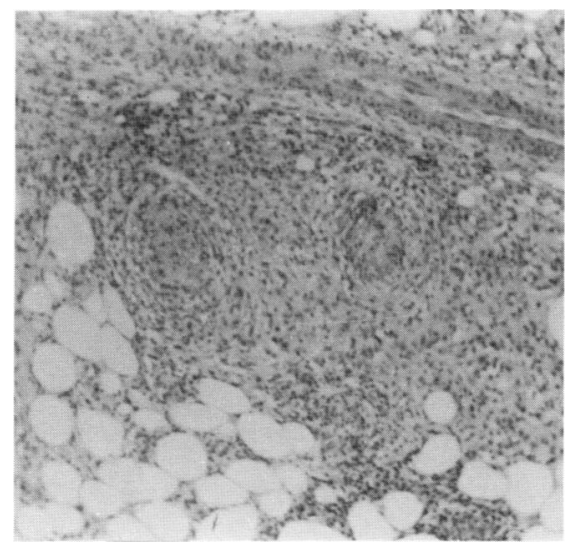

Nodular panniculitis. Some granulomata show caseous central necrosis (haematoxylin and eosin). found. ${ }^{2}$ Although $M$ tuberculosis has occasionally been isolated when erythema induratum coincides, most authors support its aetiological role. ${ }^{3}$ Nodular vasculitis is a form of multifactorial lobular panniculitis that may coexist with a tuberculous focus (erythema induratum of Bazin) or may not (nodula vasculitis erythema induratum complex) Throughout the two year follow up of our patient no nodule became ulcerated and the lesions healed with specific chemotherapy.

Rheumatoid factors in low titres are found in a small percentage of young adults. A high prevalence of $R F$ is also found in patients with chronic infections, such as syphilis, leprosy, and tuberculosis. These observations have suggested that extensive or persistent exposure to antigens and immune complex formation induces the synthesis of RF. $M$ tuberculosis antigens can induce the production of RF, and several reports have demonstrated the autoimmunogen capacity of some proteins of this microorganism particularly heat shock protein $60 .^{5}$

Immune complexes seen to have an important pathogenic role in nodular vasculitis. They have been found in patients with Henoch-Schönlein purpura associated with active tuberculous infection. ${ }^{7}$ It should be pointed out that in our patient autoimmune diseases with increased RF levels, such as rheumatoid arthritis, Sjögren's syndrome, cryoglobulinaemia, and autoimmune live disease, were excluded. Moreover, after treatment was started RF progressively fell to nearly normal values.

The persistent negativity of the Mantoux skin test deserves a special mention. It is unlikely that the patient had disseminated tuberculosis or any other immunosuppressive condition. A negative Mantoux skin test has been described in patients with erythema induratum. ${ }^{2}$ There is no doubt about the importance of the skin biopsy as it allows histological demonstration of erythema induratum and helps to establish the differentia diagnosis with erythema nodosum, syphilis foreign body granuloma, and skin tuberculosis. $^{89}$ Finally, we strongly believe that the finding of erythema induratum should prompt a diagnostic search for pulmonary or extrapulmonary involvement of tuberculous infection.

The authors thank Miss Sonia Galeron for assistance in the preparation of this manuscript.

NORBERTO GÓMEZ RODRÍGUEZ JOSÉ LUIS FERREIRO SEOANE EMILIA FORMIGO RODRÍGUEZ Rheumatology Unit Povisa Medical Center Spain

ANA DE LA FUENTE BUCETA Department of Pathology
Povisa Medical Center Spain

Correspondence to: Dr Norberto Gómez Rodriguez, Rheumatology Unit, Povisa Medical
Center, C/ Salamanca no 5, 36.211 Vigo, Spain.

1 Feiwel M, Munro D D. Diagnosis and treatment of erythema induratum (Bazin). $B M^{\mathcal{F}}$ 1965; i: $109-11$.

2 Bondi E E, Lazarus G S. Panniculitis. In: Fitzpatrick T B, Eisen A Z, Wolff K, Freedberg I N, Austen K F, eds. Dermatology in general medicine, 3rd ed. New York:

3 Hassoun P M, Shepherd K E, Flotte T T

Kazemi $\mathbf{H}$. Erythema induratum and active pulmonary tuberculosis. Am $\mathcal{f} M e d 1988 ; 84$ : pulmo 5 .

4 Bartfeld $\mathrm{H}$. Distribution of rheumatoid factor activity in non-rheumatoid states. Ann NY Acad Sci 1969; 168: 30-8.

5 Rook G, Lydyard P, Stanford J. Mycobacteria and rheumatoid arthritis. Arthritis Rheum 1990; 33: 431-5.

6 Parish W E, Rhodes M D. Bacterial antigen and aggregated gamma-globulin in the lesions of nodular vasculitis. BrF Dermatol 1967; 79. $131-47$.

7 Pacheco A, Mateos P, Medina J, Guisasola L Carrillo F, Pérez-Oleiza J. Tuberculosis pulmonar y púrpura de Schonlein-Henoch. Rev Clin Esp 1987; 180: 515

8 Niemi K M, Forstrom L Hannuksela $M$ Mustakallio K K, Salo O P. Nodules on the legs. A clinical, histological and immunohistological study of 82 patients representing different types of nodular panniculitis. Acta Derm Venereol (Stockh) 1977; 57: 145-54.

9 Harahap $M$. Tuberculosis of the skin. Int $f$ Dermatol 1983; 22: 524-45.

\section{CREST syndrome with pericardial but not peripheral calcinosis}

Sir: The CREST subgroup of systemic sclerosis is a mild or slowly progressive form of the disease characterised by calcinosis, Raynaud's phenomenon, oesophageal dysfunction, sclerodactyly, and telangiectasia. Anticentromere antibodies detected on the Hep-2 substrate appear highly selective for this group of patients. ${ }^{2}$ In the Johns Hopkins series calcinosis was present in all patients with CREST, being peripheral or around joints in the majority. ${ }^{1}$ Patients with CREST do develop internal organ manifestations but usually only in the second and third decades of their disease. ${ }^{3}$ We describe a patient with the CREST syndrome who presented with dyspnoea due to calcific pericarditis without peripheral calcinosis.

A 65 year old white female smoker presented to her general practitioner with shortness of breath in August 1989. He detected an expiratory wheeze and prescribed amoxycillin. Her pulse was 160 beats/min and she was referred to a cardiologist. She was in atrial flutter with $2: 1$ block and had signs of 'mild congestive heart failure'. The jugular venous pressure was raised $9 \mathrm{~cm}$. A chest radiograph showed a cardiothoracic ratio of $58 \%$ with upper lobe venous diversion. She was anticoagulated and cardioverted but atrial flutter recurred, and her ventricular rate was controlled with verapamil, digoxin, and a diuretic. The patient had a six year history of Raynaud's phenomenon and was noted to have facial telangiectasia and mild sclerodactyly. Further investigation showed a positive anticentromere antibody and negative antinuclear and Scl-70 (topoisomerase 1) antibodies. A barium study showed markedly reduced oesophageal motility. A diagnosis of CREST syndrome was made, though no calcinosis had been detected either clinically or radiologically. She gained symptomatic relief from wearing heated gloves and using cisapride, having been intolerant of $\mathrm{H}_{2}$ blockers.

Although there was improvement in her dyspnoea, the jugular venous pressure remained raised. In March 1991 she reported increasing shortness of breath on exertion and swelling of the legs. Her jugular venous pressure was $8 \mathrm{~cm}$ raised with a positive Kussmaul's sign and pulsus paradoxus of 30 $\mathrm{mmHg}$. A lateral chest radiograph showed marked pericardial calcification (figure) that had not been apparent on previous posteroanterior views. There was no history of tuberculosis or tuberculous contacts. The possibility of an operation to relieve her tamponade was discussed, but the patient refused. 


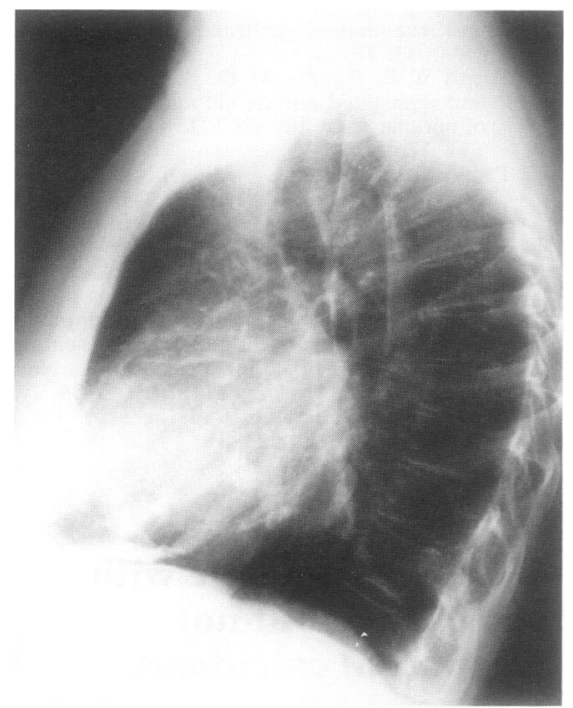

Chest radiograph showing dense pericardial calcification on the lateral view.

Within three months, however, she underwent cardiac catheterisation with simultaneous right and left heart pressure measurements which showed the characteristic dip and plateau configuration of constrictive pericarditis. A pericardiectomy was performed and she made an uneventfu recovery. On returning to full activity she again complained of shortness of breath on exertion. Physical examination and chest radiography showed no evidence of residual pericardial constriction. Spirometry, however, showed an obstructive picture with forced expiratory volume in one second of 0.85 litres and forced vital capacity of 1.6 litres. Her symptoms improved considerably with bronchodilator treatment. Respiratory function tests showed reduced lung volumes and an obstructive defect. The peak flow improved from 145 to $200 \mathrm{l} / \mathrm{min}$ (predicted $319 \mathrm{l} / \mathrm{min}$ ) after nebulised salbutamol. The corrected transfer factor was only marginally reduced, making significant pulmonary vascular disease unlikely.

Our patient's deteriorating exertional dyspnoea and increasing oedema in 1991 were due to pericardial constriction and once this had been surgically relieved the presence of obstructive airways disease was unmasked. Pericardial disease occurs in about $50 \%$ of patients with systemic sclerosis ${ }^{4}$ and only slightly less commonly (38\%) in patients with CREST. ${ }^{5}$ Only a third of these patients are symptomatic, however. ${ }^{6}$ As far as we know, this is the first reported case of calcific constrictive pericarditis in the CREST syndrome and is particularly unusual in that our patient had no evidence of peripheral calcification.

Lung involvement in systemic sclerosis was recognised shortly after the original description of the disease ${ }^{7}$ and is found with a similar prevalence in patients with CREST. Although large airways obstruction in CREST syndrome and systemic sclerosis has been well described, response to bronchodilator treatment is poorly documented. ${ }^{7} \mathrm{~A}$ small number of children with systemic sclerosis have had bronchodilator responsive obstructive airways disease. ${ }^{9}$ Our patient's incomplete but appreciable response and symptomatic improvement suggests that bronchodilators may be helpful in this situation.

H G TAYLOR

Department of Medicine Wanganui Base Hospital Wanganui New Zealand
P SHELDON

Department of Rheumatology Leicester Royal Infirmary

Leicester

A J McCANCE
J D SKEHAN
Department of Cardiology
Groby Road Hospital
Leicester

Leicester

Correspondence to: Dr H G Taylor, Department of Medicine, Wanganui Base Hospital, Private Bag, Wanganui, New Zealand.

1 Tan E M, Rodnan G P, Garcia I, Moroi Y Fritzler M J, Peebles C. Diversity of antinuclear antibodies in progressive systemic sclerosis: anti-centromere antibody and its relationship to CREST syndrome. Arthritis Rheum 1980; 23: 617-25.

2 Velayos E E, Masi A T, Stevens M B, Shulman L E. The "CREST" syndrome. Comparison $\mathrm{L}$. The "CREST" syndrome. Comparison
with systemic sclerosis (scleroderma). Arch with systemic sclerosis (scler

3 Salerni R, Rodnan G P, Leon D F, Shaver J A. Pulmonary hypertension in the CREST syndrome variant of progressive systemic sclerosis (scleroderma). Ann Intern Med 1977; 86:394-9.

4 Botstein G R, LeRoy E C. Primary heart disease in systemic sclerosis (scleroderma): advances in clinical and pathologic features, pathogenesis, and new therapeutic approaches. $A m$ Heart f 1981; 102: 913-9.

5 Smith J W, Clements P J, Leviman J, Furst D, Ross M. Echocardiographic features of progressive systemic sclerosis (PSS) - correlation with haemodynamic and postmortem studies. Am 7 Med 1979; 66: 28-33.

6 McWhorter J E, Le Roy E C. Pericardial disease in scleroderma (systemic sclerosis). Am $\mathcal{J} M e d$ 1974; 57: 566-75.

7 Owens G R, Follansbee W P. Cardiopulmonary manifestations of systemic sclerosis. Che 1987; 91: 118-27.

8 Owens G R, Fino G F, Herbert D L, et al. Pulmonary function in progressive systemic sclerosis. Comparison of CREST syndrome variant with diffuse scleroderma. Chest 1983 84: 546-50.

9 Garty B-Z, Athreya B H, Wilmott R, Scarpa N, Doughty R, Douglas S D. Pulmonary functions in children with progressive systemic sclerosis. Pediatrics 1991; 88: 1161-7. 